\title{
Androgen deprivation therapy in high risk prostate cancer
}

\author{
Ritchell Van Dams, Amar U. Kishan \\ Department of Radiation Oncology, University of California, Los Angeles, CA, USA \\ Correspondence to: Amar U. Kishan, MD. 200 UCLA Medical Plaza, Suite B265, Los Angeles, CA 90095, USA. Email: aukishan@mednet.ucla.edu. \\ Response to: Kim DK, Kim YH, Kim JH. Effects of androgen deprivation therapy duration and Gleason grade on survival outcomes of high risk \\ prostate cancer. Transl Cancer Res 2019;8:715-8.
}

Submitted Jun 06, 2019. Accepted for publication Jun 12, 2019.

doi: $10.21037 /$ tcr.2019.06.37

View this article at: http://dx.doi.org/10.21037/tcr.2019.06.37

We thank Dr. Kim and colleagues for their interest in our study $(1,2)$. The authors mention some limitations of our study, all of which were discussed in our initial report, but can be discussed further. First, however, it is worth noting that the central conclusion of the study is not necessarily that patients with Gleason grade group (GG) 5 tumors need lifelong androgen deprivation therapy (ADT), but rather that GG 5 tumors are not inherently resistant to ADT, as had been previously suggested (3). If they were truly resistant, then lifelong ADT would have no impact on endpoints such as distant metastasis or prostate cancerspecific mortality, let alone overall survival, particularly given the known adverse sequelae of ADT that Kim et al. mention (2). Instead, it is entirely possible that GG 5 tumors require more potent androgen inhibition to achieve the level of control that is seen with GG 4 tumors with less intensive/shorter duration ADT-consistent with a Gleason grade-dependent effect of ADT, in the context of definitive radiotherapy (RT). Thus, we support ongoing efforts to determine strategies that seek to maximize the efficacy of ADT while limiting its duration. This is the same conclusion that Kim et al. propose in their own Summary and Conclusions (2).

Second, although there was a lack of central pathologic review across all patients in this meta-analysis, only two of the six trials in the analysis did not include central pathologic review within the trial comprising approximately $27 \%$ of the total analyzed cohort $(4,5)$. Although this lack of central review between studies does present a limitation with respect to concordance between the cohorts as well as changes to the Gleason grading system over time, the vast majority of patients analyzed in this study had their pathology centrally reviewed which allows for reliable comparison of treatment effect within each cohort. A more general problem regarding determination of ADT duration with definitive RT is the demonstration of discordance between biopsy Gleason grade and surgical Gleason grade as seen after radical prostatectomy (6). Although this discordance remains worrisome with respect to accurate risk classification of patients and additional work is needed to improve accuracy and concordance of biopsy Gleason grade, all prior investigations of prostate cancer treatment response to definitive RT with or without ADT-including the six studies included in this meta-analysis-rely on biopsy Gleason grade. Thus, this is not a limitation of our study, but a limitation of all trials and in fact a limitation of definitive RT for prostate cancer in general. Further, discordances between biopsy Gleason grade and "ground truth" surgical Gleason grade (had these patients undergone prostatectomy) would be unexpected to lead to the consistent result of worse outcomes (including OS) between GG 5 and GG 4 tumors.

Finally, the use of substandard radiation doses and the high enrichment of tumors with locally advanced lesions is again a valid point. However, these six trials are routinely used to justify the current standard of care for the management of high-risk prostate cancer with definitive RT. Therefore, those limitations apply not only to this metaanalysis, but to the data foundation used to drive current treatment guidelines. Within this context, our conclusions are relevant to modern practice. 


\section{Acknowledgments}

Funding: None.

\section{Footnote}

Provenance and Peer Review: This is an invited article commissioned and reviewed by the Section Editor HongChao He (Department of Urology, Shanghai Ruijin Hospital, Shanghai Jiaotong University School of Medicine, Shanghai, China).

Conflicts of Interest: AU Kishan: Honoraria from Varian Medical Systems, Inc., ViewRay, Inc. and Advisory Board for Jannsen, Inc. The other author has no conflicts of interest to declare.

Ethical Statement: The authors are accountable for all aspects of the work in ensuring that questions related to the accuracy or integrity of any part of the work are appropriately investigated and resolved.

Open Access Statement: This is an Open Access article distributed in accordance with the Creative Commons Attribution-NonCommercial-NoDerivs 4.0 International License (CC BY-NC-ND 4.0), which permits the noncommercial replication and distribution of the article with the strict proviso that no changes or edits are made and the original work is properly cited (including links to both the formal publication through the relevant DOI and the license). See: https://creativecommons.org/licenses/by-nc-nd/4.0/.

\section{References}

1. Kishan AU, Wang X, Seiferheld W, et al. Association of Gleason Grade With Androgen Deprivation Therapy Duration and Survival Outcomes. JAMA Oncol 2019;5:91.

2. Kim DK, Kim YH, Kim JH. Effects of androgen deprivation therapy duration and Gleason grade on survival outcomes of high risk prostate cancer. Transl Cancer Res 2019;8:715-8.

3. D'Amico AV. Is Gleason Grade 5 Prostate Cancer Resistant to Conventional Androgen Deprivation Therapy? Eur Urol 2016;69:761-3.

4. Bolla M, de Reijke TM, Van Tienhoven G, et al. Duration of androgen suppression in the treatment of prostate cancer. N Engl J Med 2009;360:2516-27.

5. Bolla M, Maingon P, Carrie C, et al. Short Androgen Suppression and Radiation Dose Escalation for Intermediate- and High-Risk Localized Prostate Cancer: Results of EORTC Trial 22991. J Clin Oncol 2016;34:1748-56.

6. King CR. Patterns of prostate cancer biopsy grading: trends and clinical implications. Int J Cancer 2000;90:305-11.
Cite this article as: Van Dams R, Kishan AU. Androgen deprivation therapy in high risk prostate cancer. Transl Cancer Res 2019;8(5):2216-2217. doi: 10.21037/tcr.2019.06.37 